\title{
Estimating proportion of clones and genotype richness in aquatic microalgae
}

\author{
Ingrid Sassenhagen ${ }^{1}$, Deana Erdner ${ }^{2}$, Bryan Lougheed ${ }^{3}$, Mindy Richlen ${ }^{4}$, and Conny \\ Sjöqvist ${ }^{5}$
}

${ }^{1}$ Uppsala University Faculty of Science and Technology

${ }^{2}$ The University of Texas at Austin

${ }^{3}$ Uppsala Universitet

${ }^{4}$ Woods Hole Oceanographic Institution

$5^{\circ}$ Abo Akademi University

April 18, 2021

\begin{abstract}
Although the majority of microalgal species reproduce asexually for large parts of the growth season, most population genetic studies have rarely found clones in microalgal blooms. Instead, population genetic studies have identified large intraspecific diversity in most microalgal species. This paradox of frequent asexual reproduction but low number of clones creates challenges when interpreting the proportion of clones and distinct genotypes in natural microalgal populations. To estimate the proportion of clones and genotype richness, we created a computer model that simulates the composition of microalgal populations after a defined period of exponential growth. We simulated the probability of picking clones of the same genotype from this population as a function of initial genotype diversity, intraspecific differences in growth rates and sample size. This model was applied to five microalgal species for which high-resolution population genetic data and population growth rates based on monitoring data were available. The number of distinct genotypes in each population was extrapolated from the model outputs and the observed proportion of clones in the respective population genetic studies. The estimates from our simulation suggested that the genotype richness in most blooms exceeds several thousand distinct genotypes with very high variability among microalgal species. The highest numbers of distinct genotypes (500,000 and 2,000,000 genotypes) were estimated for species with very low numbers of observed clones in population genetic studies $(<5 \%)$, but genotype richness was also strongly impacted by intraspecific variability in growth rates. Furthermore, the probability of finding clones and presumably sampling a representative fraction of genotypes increased significantly with higher sample sizes, challenging the detection of differences in genotype diversity between sub-samples with few isolates.
\end{abstract}

\section{Hosted file}

manuscript8.pdf available at https://authorea.com/users/408556/articles/518513-estimatingproportion-of-clones-and-genotype-richness-in-aquatic-microalgae

Hosted file

Table1.xlsx available at https://authorea.com/users/408556/articles/518513-estimatingproportion-of-clones-and-genotype-richness-in-aquatic-microalgae

\section{Hosted file}

Figures.pdf available at https://authorea.com/users/408556/articles/518513-estimatingproportion-of-clones-and-genotype-richness-in-aquatic-microalgae 